\title{
MATHEMATICAL MODELLING OF A TRANSPORT SYSTEM WITH MINIMAL MAINTENANCE COSTS
}

\author{
A.I. Kibzun, Moscow Aviation Institute, Moscow, Russian Federation, kibzun@mail.ru, \\ O.M. Khromova, Moscow Aviation Institute, Moscow, Russian Federation, \\ khromova-om@mail.ru
}

\begin{abstract}
We suggest a mathematical model of a transport system. The model describes the delivery of products from several suppliers to different points of consumption. It is assumed that consumer demands are random. The model is a two-stage stochastic programming problem. At the first stage suppliers make the commodity stocks. At the second stage we consider the product distribution to the points of consumption while minimizing compensation expenses for the goods shortage caused by the random demand. The model takes into account a random loss that occurs during the transportation of goods and the detection of defective products. The total cost of the transport system operation is minimized. The algorithm for solving the problem is proposed. This algorithm is based on reduction of the original problem to an equivalent mixed-integer linear programming problem after discretization. An example is considered.

Keywords: mathematical modelling; stochastic programming; quantile function; twostage problem; transport problem.
\end{abstract}

\section{Introduction}

Complicated mathematical models can be used to describe the difficult socio-economic objects and processes. As an example, the problem of minimizing the cost of products transportation between storage points and points of consumption can be described by a mathematical model of the transport system. There is a class of the "transport problems" which is applied not only to the traffic optimization. Models of this type were initially used to find the minimum of a total transportation cost in case of consumers and suppliers interaction (see [1]).

Recently the stochastic models were widely used in different applied economic problems. As an example, the mathematical model of the transport system taking into account the random demand for products in points of consumption can be described by a stochastic model. The similar problems with random parameters are quite often solved by mathematical programming methods. The criterion of mathematical expectation is the most commonly used as a criterion for stochastic programming problems. This criterion shows the average effect of the taken decisions, so the one means the average value of the loss function. This criterion is appropriate to apply when a mathematical model of the problem contains a significant number of objects with offsetting random deviations. The transport problem with the mathematical expectation criterion is considered in $[2,3]$.

However, the probabilistic or the quintile criterion can be selected as a criterion in the stochastic problems. Probabilistic criterion characterizes the probability of the exceedance of a given level of loss. When we use a probabilistic criterion, we fix the efficiency of the system at a certain acceptable level of loss and then we maximize the probability of this level exceedance. Thus we maximize the system reliability. The quantile criterion is the loss level which will be not exceeded with a given probability. The quantile problem and 
the probability problem are reversed. So in the quintile problem we limit the reliability of the system at a certain acceptable level and optimize the effectiveness of the strategy. Features quantile and probability criteria are studied in detail in book [4].

The transport problem with the stochastic mathematical model can be regarded as a one-stage or in multistage form. In the one-stage stochastic programming problems the decision is made once and does not depend on dynamic and sequence of incoming information flow about the realization of the system's random parameters. This decision can not be corrected after receiving information about the realization of the random factors. The traditional transport problem with the one-stage planning structure is given in $[2]$.

The multistage problem takes into account information of dynamics of the system decision and the one allows to correct the initial decision on the next stage. The multistage structure of the transport problem can be arisen by the random nature of the system characteristics that determine the state of the system at each time point as well as the lack of information about future realizations of random model parameters. In this case, at the first stage a preliminary plan is developed, i.e. a preliminary problem decision is chosen. This decision will be corrected in the following stages of the problem, taking into account the incoming information about the behavior of the system according to the decision implementation. Example of the two-stage transport problem with the quantile function can be found in [5].

This paper discusses the two-stage optimization transport problem with quantile criterion and with bilinear loss function. It is assumed that the consumer demands are random and have the uniform distribution, which is the least favorable for the decision maker [4]. We reduce the original problem to an equivalent mixed integer linear programming problem, using the confidential method described in [4] and the results obtained in [6,7], based on the results of $[8,9]$. The optimization of the transport system for different brands of hair dryers delivery on each of the suppliers to consumers are considered as an example.

\section{A Formulation of the Problem}

Suppose that there are several suppliers, each of which offers the same type of products at a specified cost. Let all providers included in a single company cooperate with a fixed number of consumers. Each consumer is interested in purchasing products from multiple suppliers. This is due to the different cost of suppliers production and the wish of the diverse range of products for each consumer. In the present paper the consumers are supposed to be small commercial organizations, individual entrepreneurs, micro business, so they carry out their purchases to the end-users after receiving the products from the suppliers.

Consider the problem from the suppliers point of view. During the certain period of time (e.g., 1 month) providers need to implement their existing products while meeting consumer demand. The demand for products is a random variable with a known distribution function. Sometimes the consumer demand is not satisfied. It can take place in cases of the lack of the suppliers goods, and loss of the product quality during transportation or detection of an internal defect of the goods. After that the suppliers have to deliver the missing goods to consumers. At the same time the providers pay 
additional purchases and the subsequent product transportation at a higher cost due to the urgency of execution. Consumers receive their goods on the initial ordered cost, but in a different date. The loss that arises during the period of work is the criterion for the efficiency of the suppliers work.

Operation of the system in each given period of time can be described as a two-stage problem. On the first stage the suppliers form a preliminary supply plan based on the known value of the costs of suppliers for the acquisition, storage and delivery of products. The delivery includes the costs of gasoline, based on the calculation of transport distance, pay a rent and transporter vehicle work. On the second stage, the random consumer demand arising after the implementation of the initial plan providers are satisfied. The unsatisfied demand is compensated by the urgent procurement and delivery of goods to the consumer using a more higher cost for the supplier.

Suppose that the interaction of $I$ suppliers and $J$ consumers is considered in the transport system. The costs of the products delivery from all providers to the $j$-th consumer, $j=\overline{1, J}$, can be described as a vector $c_{0 j}$ of size $I$.

The costs of the suppliers are dependent on the external factors affecting on the purchase price of the product and the costs associated with transportation. This random external influence can be taken into account in the preliminary plan of supplies in the form of a random vector $Z_{j} \in \mathbb{R}^{I}, Z_{j} \triangleq \operatorname{col}\left(Z_{j 1}, \ldots, Z_{j I}\right)$. This vector is characterized by a random addition to the cost of the supplier, which can occur in the case of the initial purchase cost of the goods changes, transportation products price increases. We assume that $Z_{j}=\max \left\{-c_{0 j}, \bar{Z}_{j}\right\}$, where $\bar{Z}_{j} \sim \mathcal{N}\left(m_{j}, K_{j}\right), j=\overline{1, J}$, because of the addition to the random value may deviate from its average value in large and in the smaller side with an equal probability, but can not be less than $-c_{0 j}$.

Let the random values $Z_{j i}$ be independent, $Z \triangleq \operatorname{col}\left(Z_{1}, \ldots, Z_{J}\right), i=\overline{1, I}, j=\overline{1, J}$.

Let the vector $u_{j} \triangleq \operatorname{col}\left(u_{j 1}, \ldots, u_{j I}\right), j=\overline{1, J}$, characterize the number of goods delivered to the $j$-th consumer from all suppliers, $u \triangleq \operatorname{col}\left(u_{1}, \ldots, u_{J}\right)$. This vector is based on the planned value $u_{j i}, j=\overline{1, J}, i=\overline{1, I}$, of products for the $j$-th customer from the $i$-th supplier. Assume that the total stock of the products for the $j$-th customer is limited, that is $u \in U$, where

$$
U \triangleq\left\{u \in \mathbb{R}^{J \cdot I}: u_{j i} \geq 0, \sum_{i=1}^{I} u_{j i} \leq d_{j}, \sum_{j=1}^{J} u_{j i} \leq h_{i}\right\},
$$

the value $d_{j}, j=\overline{1, J}$, characterizes the limited purchasing power of the $j$-th customer, the value $h_{i}, i=\overline{1, I}$, is a limited stock in warehouses of the $i$-th supplier. Note that the set $U$ is a compact set.

According to the designations introduced above the loss function of the suppliers on the first stage can be formulated in the form:

$$
\Phi_{1}(u, Z)=\sum_{j=1}^{J}\left(c_{0 j}^{T}+Z_{j}^{T}\right) u_{j}
$$

Suppose that the suppliers can know about the real demand of the consumers for their products in this period of time on the second stage. There are three cases of the demand 
realization. First, when the consumer demand coincided with the expected demand; second, when the consumer demand is lower than the expected value, and the third, when consumer demand significantly exceeds the planned value of deliveries. In the first case any additional actions from the suppliers are not required since the preliminary plan was made correctly. In the second case the suppliers need to store the rest of the product. In the third case suppliers need to compensate the lack of production to meet the demand of customers urgently. The third case is also a result of non accurate products transportation, damage of the product during transportation or a hidden defect, which can be established only after the receipt of the product by consumers.

Introduce the vector $y_{j} \triangleq \operatorname{col}\left(y_{j 1}, \ldots, y_{j I}\right), y_{j} \geq 0, j=\overline{1, J}, y \triangleq \operatorname{col}\left(y_{1}, \ldots, y_{J}\right)$, to describe the strategy of the suppliers on the second stage. This vector characterizes the additional supply of goods to meet the consumer's demand. Let $c_{1 j}$ be a deterministic vector of size $I$ corresponding to the cost of emergency missing product delivery to the $j$-th consumer from all $I$ suppliers. Then the loss function for the second stage

$$
\Phi_{2}(y)=\sum_{j=1}^{J} c_{1 j}^{T} y_{j} .
$$

Let the random vector $X=\operatorname{col}\left(X_{1}, \ldots, X_{J}\right)$ be a continuous random vector characterizing the occasional demand for products of all suppliers, where $X_{j}$ characterizes the random demand of the $j$-th consumer for the products of all suppliers, $j=\overline{1, J}$. The demand for the products can be measured in kilo, pieces, product batches, etc. It can be assumed that the demand has the unimodal property. There are various versions of the demand distribution law in the mathematical works. For example, the demand has the normal distribution in [10], and the uniform distribution in [11]. In case of the unimodal distribution the uniform distribution is the worst distribution for the decision maker (see [4]). In terms of real interaction between suppliers and consumers it is advisable to consider the worst-case of the demand realization to the formation of the preliminary supply plan. In that case the supplier will not incur significant loss associated with the unsatisfied demand. Therefore, assume that the demand is stable and limited by the following inequality: $0 \leq a_{j} \leq X_{j} \leq b_{j}, j=\overline{1, J}$, i.e., $X_{j} \sim \mathcal{R}\left(a_{j} ; b_{j}\right)$. We also assume that the demands $X_{j}, j=\overline{1, J}$, of different consumers are independent.

The second stage takes into account the preliminary plan from the first stage and the information about the share of damaged during the transportation of products or products with a hidden defect. This information can be considered as a random vector $W_{j} \triangleq \operatorname{col}\left(W_{j 1}, \ldots, W_{j I}\right), j=\overline{1, J}$. Let $W \triangleq \operatorname{col}\left(W_{1}, \ldots, W_{J}\right)$. The total number of the defective products is characterized by $W_{j i}=\min \left\{1, \bar{W}_{j i}\right\}$, where $\bar{W}_{j i} \sim \mathcal{E}\left(\lambda_{j i}\right), j=\overline{1, J}$, $i=\overline{1, I}$, is the share of the identified defective products, $1 / \lambda_{j i}$ is the average percentage of defective products. Assume that all the $W_{j i}$ are independent. Select the exponential distribution for the possible damage during product transportation according to the rare expected cases of damaged products or the products with a hidden defect.

We require that the demand on the second stage is satisfied:

$$
\left(e_{0}^{T}-W_{j}^{T}\right) u_{j}+e_{0}^{T} y_{j} \geq X_{j}, j=\overline{1, J}
$$

where $e_{0} \triangleq \operatorname{col}(1, \ldots, 1), e_{0} \in \mathbb{R}^{I}$. 
Let $\mathcal{Y}(u, X, W)$ be the set of feasible strategies of the second stage with constraints (3) and $y_{j} \geq 0$.

Using the results introduced above we write the optimization model of the transport system in terms of suppliers. The total value of suppliers costs on the first and second stages of the problem is equal to

$$
\Phi(u, Z, X, W) \triangleq \sum_{j=1}^{J}\left(c_{0 j}^{T}+Z_{j}^{T}\right) u_{j}+\inf _{y \in \mathcal{Y}(u, X, W)} \sum_{j=1}^{J} c_{1 j}^{T} y_{j},
$$

where

$$
\mathcal{Y}(u, X, W) \triangleq\left\{y \in \mathbb{R}^{J \cdot I}:\left(e_{0}^{T}-W_{j}^{T}\right) u_{j}+e_{0}^{T} y_{j} \geq X_{j}, y_{j} \geq 0, j=\overline{1, J}\right\},
$$

$\Phi(u, Z, X, W)$ is the loss function of the suppliers which depends on the first stage strategy $u$ and the optimal strategy $y$ of the second stage. We consider the problem from the suppliers point of view so it is logical to minimize the total loss of the suppliers. That is why we minimize the loss function on the second stage.

The general form of the similar loss function is considered in [6,7]. In order to show the similarity of the present problem and the problems from $[6,7]$ we introduce the following notation. Suppose that $c_{0} \triangleq \operatorname{col}\left(c_{01}, \ldots, c_{0 J}\right), c_{1} \triangleq \operatorname{col}\left(c_{11}, \ldots, c_{1 J}\right)$,

$$
B \triangleq\left(\begin{array}{cccc}
e_{0}^{T} & 0 & \ldots & 0 \\
0 & e_{0}^{T} & \ldots & 0 \\
\ldots & \ldots & \ldots & \ldots \\
0 & 0 & \ldots & e_{0}^{T}
\end{array}\right)
$$

Then loss function (4) can be written as

$$
\Phi(u, Z, X, W)=\left(c_{0}^{\mathrm{T}}+Z^{T}\right) u+\inf _{y \in \mathcal{Y}(u, X, W)} c_{1}^{T} y
$$

with the constraints for the second stage

$$
\mathcal{Y}(u, X, W) \triangleq\{y: A u-C(W) u+B y \geq X, y \geq 0\},
$$

where $A=B$,

$$
C(W) \triangleq\left(\begin{array}{cccc}
W_{1}^{T} & 0 & \ldots & 0 \\
0 & W_{2}^{T} & \ldots & 0 \\
\ldots & \ldots & \ldots & \ldots \\
0 & 0 & \ldots & W_{J}^{T}
\end{array}\right)
$$

Consider the probability function

$$
P_{\varphi}(u) \triangleq \mathcal{P}\{\Phi(u, Z, X, W) \leq \varphi\}
$$

which characterizes the probability of such an event, when the total loss will not exceed a given level $\varphi$.

Consider the quantile function

$$
\varphi_{\alpha}(u) \triangleq \min _{\varphi}\left\{\varphi: P_{\varphi}(u) \geq \alpha\right\}, \alpha \in(0,1)
$$


which characterizes the level $\varphi$ of loss, which will be not exceeded with the probability $\alpha$.

The strategy optimization problem at the first stage is as follows

$$
u_{\alpha}=\arg \min _{u \in U} \varphi_{\alpha}(u), \varphi_{\alpha}=\min _{u \in U} \varphi_{\alpha}(u), \alpha \in(0,1) .
$$

Thus, the formulated problem is the same in structure with the problem in $[6,7]$. Therefore, we can use the problem solving technique, set out in $[6,7]$.

\section{Reduction to a Mixed Integer Programming Problem}

According to the confidence method (see [4]), problem (10) is equivalent to the following minimax problem

$$
\begin{gathered}
\varphi_{\alpha}=\min _{u \in U}\left[\min _{E \in \mathcal{E}_{\alpha}} \psi(E, u)\right], \\
\psi(E, u) \triangleq \sum_{j=1}^{J} c_{0 j}^{T} u_{j}+\sup _{\bar{x} \in E} \bar{\Phi}(u, \bar{x}),
\end{gathered}
$$

where $\bar{x} \triangleq \operatorname{col}(z, x, w), E$ is a confidence set with probability measure $\alpha$ from $\mathbb{R}^{J+2 I \cdot J}$,

$$
\bar{\Phi}(u, \bar{x}) \triangleq \sum_{j=1}^{J} z_{j}^{T} u_{j}+\min _{y \in \mathcal{Y}(u, x, w)} \sum_{j=1}^{J} c_{1 j}^{T} y_{j},
$$

$\mathcal{E}_{\alpha}$ is the family of sets with the measure $\alpha, \mathcal{E}_{\alpha} \triangleq\{E: \mathcal{P}(E) \geq \alpha\}$, vectors $z, x, w$ are realizations of the random vectors $Z, X, W$.

Since the set $U$ of feasible strategies is compact and loss function (4) is continuous, the loss function for the second stage is lower semi-continuous (see [12]). According to Theorem 2.2 [4] the minimum in problem (10) is reached. Therefore, the search of the exact lower bound for problem (4) can be replaced by the search of the minimum of function (11).

Here, the equivalence has the following sense (see [6]).

Definition 1. We will say that two optimization problems are equivalent, if the following conditions hold:

(i) either both the problems have some feasible solutions (with finite values of objective functions) or both the problems have no feasible solutions;

(ii) if these problems have some feasible solutions, then optimal values (finite or infinite) of both the objective functions coincide;

(iii) if the optimal values of both the objective functions are finite, then either these values are attained or they are not attained;

(iv) if the optimal values are attained, then every optimal solution of one problem can be reconstructed by using some algorithm into an optimal solution of the other problem;

(v) if the optimal values of both the objective functions are finite but they are not attained, then every optimizing sequence for one problem can be reconstructed by using some algorithm into an optimizing sequence for the other problem.

Consider a set $E \in \mathcal{E}_{\alpha}$ and the minimax problem

$$
\psi_{E}=\min _{u \in U} \psi(E, u), u^{E}=\arg \min _{u \in U} \psi(E, u) .
$$


According to the confidence method (see [4]) the following inequalities

$$
\varphi_{\alpha} \leq \varphi_{\alpha}\left(u^{E}\right) \leq \psi_{E}
$$

hold, and there is an optimal set $E_{\alpha} \in \mathcal{E}_{\alpha}$, where $\psi_{E_{\alpha}}=\varphi_{\alpha}$.

Let us use dual variables $v \in \mathbb{R}^{J}, j=\overline{1, J}$, in the problem of the second stage. According to [13] let us consider the set

$$
V \triangleq\left\{v \in \mathbb{R}^{J}: B^{T} v \leq c_{1}, v_{j} \geq 0, j=\overline{1, J}\right\}
$$

where $B$ is a matrix of size $J \times(J \cdot I)$ and looks like (6).

The structure of the matrix $B$ determines that the set

$$
V=\left\{v \in \mathbb{R}^{J}: 0 \leq v_{j} \leq \min _{i=\overline{1, I}} c_{1 j i}, j=\overline{1, J}\right\}
$$

is the $J$-dimensional rectangle with vertices $v^{s}$, where $s=\overline{1, S}, S \triangleq 2^{J}$.

Using the theory of duality [13] we can get the equivalent dual problem for the second stage:

$$
\overline{\bar{\Phi}}(u, x, w)=\max _{v \in V} \bar{a}^{T}(u, x, w) v,
$$

where

$$
\overline{\bar{\Phi}}(u, x, w)=\bar{\Phi}(u, \bar{x})-\sum_{j=1}^{J} z_{j}^{T} u_{j}, \bar{a}(u, x, w) \triangleq\left(\begin{array}{c}
x_{1}+w_{1}^{T} u_{1}-e_{0}^{T} u_{1} \\
\ldots \\
x_{J}+w_{J}^{T} u_{J}-e_{0}^{T} u_{J}
\end{array}\right)
$$

The polyhedron $V$ is convex. Since the function $\bar{a}^{T}(u, x, w) v$ is linear, its maximum on $V$ is attained in one of the vertices of $V$ :

$$
\overline{\bar{\Phi}}(u, x, w)=\max _{s=1, S} \bar{a}^{T}(u, x, w) v^{s}
$$

where $S=2^{J}$. Note that the elements of the vector-function $\bar{a}(u, x, w)$ are linear in $x, w$ and $u$, separately, i.e., the structure of the function $\bar{a}(u, x, w)$ is bilinear.

In the same manner as in [6], let us discretize the probability measure of the random vector $\bar{X} \triangleq \operatorname{col}(Z, X, W)$. Generate $R$ points $\bar{x}^{r}, r=\overline{1, R}$, in accordance with the density of the random vector $\bar{X}$, where $p_{r} \triangleq \mathcal{P}\left\{\bar{X}=\bar{x}^{r}\right\}=1 / R, r=\overline{1, R}$, are measures of these points.

Since the probability measure is discretized let us consider the points $\bar{x}^{r}$ which fall within the set $E$. Without loss of generality we assume that the points $\bar{x}^{r}$ correspond to the first $R_{1}$ points. Then maximum function (12) is equal to

$$
\psi(E, u)=\sum_{j=1}^{J} c_{0 j}^{T} u_{j}+\max _{r=1, R_{1}}\left[\sum_{j=1}^{J} u_{j}^{T} z_{j}^{r}+\max _{s=1, S}\left\{\bar{a}^{T}\left(u, x^{r}, w^{r}\right) v^{s}\right\}\right] .
$$

Thus problem (14) can be reduced to the problem

$$
\psi \rightarrow \min _{u \in U, \psi \in \mathbb{R}^{1}}
$$


with constraints

$$
\sum_{j=1}^{J} c_{0 j}^{T} u_{j}+\sum_{j=1}^{J} u_{j}^{T} z_{j}^{r}+\bar{a}^{T}\left(u, x^{r}, w^{r}\right) v^{s} \leq \psi, r=\overline{1, R_{1}}, s=\overline{1, S} .
$$

Note that $E \in \overline{\mathcal{E}}_{\alpha}$ is a confidence set, i.e., $\overline{\mathcal{P}}(E) \geq \alpha$, where $\overline{\mathcal{P}}$ is the discrete measure, $\overline{\mathcal{E}}_{\alpha}$ is the family of sets with the discrete probability measure $\alpha$, which is not less than $\alpha$. Let us find an optimal confidence set $E_{\alpha}$. For this purpose we introduce Boolean variables which characterize the membership of points $\bar{x}^{r}$ to the confidence set $E$ :

$$
\delta_{r} \triangleq \begin{cases}1, & \text { if } \bar{x}^{r} \in E \\ 0, & \text { otherwise }\end{cases}
$$

Then a set of variables $\delta_{r}$ from the set $E \in \overline{\mathcal{E}}_{\alpha}$ must satisfy the condition

$$
\sum_{r=1}^{R} p_{r} \delta_{r}=\frac{1}{R} \sum_{r=1}^{R} \delta_{r} \geq \alpha
$$

Suppose that we know a value $\gamma>-\infty$ which is a lower bound of the following function

$$
\gamma \leq \sum_{j=1}^{J} u_{j}^{T} z_{j}^{r}+\bar{a}^{T}\left(u, x^{r}, w^{r}\right) v^{s}, r=\overline{1, R}, s=\overline{1, S}, u \in U
$$

Then taking into account the confidence method [4] we can get the following problem

$$
\hat{\varphi}_{\alpha}=\min _{u \in U} \min _{E \in \overline{\mathcal{E}}_{\alpha}} \psi(E, u)=\min _{u \in U} \hat{\varphi}_{\alpha}(u),
$$

where $\hat{\varphi}_{\alpha}$ is an estimation of $\varphi_{\alpha}$ for the discretized measure. So, we have the problem

$$
\psi_{\alpha}=\arg \min _{\psi \in \mathbb{R}^{1}}\left[\min _{u \in U, \delta_{1}, \ldots, \delta_{R} \in\{0,1\}} \psi\right]
$$

with constraints

$$
\begin{gathered}
\sum_{j=1}^{J} c_{0 j}^{T} u_{j}+\gamma+\delta_{r}\left[\sum_{j=1}^{J} u_{j}^{T} z_{j}^{r}+\bar{a}^{T}\left(u, x^{r}, w^{r}\right) v^{s}-\gamma\right] \leq \psi, r=\overline{1, R}, s=\overline{1, S} \\
\frac{1}{R} \sum_{r=1}^{R} \delta_{r} \geq \alpha, r=\overline{1, R} .
\end{gathered}
$$

This problem is the mixed integer linear programming problem which is the linear programming problem for a fixed set $\left\{\delta_{r}\right\}_{r=1}^{R}$, where condition (20) is satisfied.

Finally, we can formulate the following statement based on statements of [6-9] and Definition 1.

Theorem 1. Quantile optimization problem (17) is equivalent to mixed integer programming problem (18) and $\psi_{\alpha}=\hat{\varphi}_{\alpha}$. 
Let us simplify the set of constraints (19) excluding the search of the vertices $v^{s}$, $s=\overline{1, S}$. For this purpose we use the structure of constraints (5) and another way of obtaining the function $\overline{\bar{\Phi}}(u, x, w)$. According to (13), (15), (16) we can get

$$
\overline{\bar{\Phi}}(u, x, w)=\min _{y \in \mathcal{Y}(u, x, w)} \sum_{j=1}^{J} c_{1 j}^{T} y_{j} .
$$

Let us introduce the following notation

$$
i_{j}^{*}=\arg \min _{1 \leq i \leq I} c_{1 j i}, y_{j}^{*}=\operatorname{col}\left(y_{j 1}^{*}, \ldots, y_{j I}^{*}\right), j=\overline{1, J},
$$

where

$$
y_{j i}^{*} \triangleq\left\{\begin{array}{cl}
\max \left\{x_{j}^{r}+u_{j}^{T} w_{j}^{r}-e_{0}^{T} u_{j}, 0\right\}, & \text { if } i=i_{j}^{*}, \\
0, & \text { otherwise. }
\end{array}\right.
$$

According to constraint (5) the minimum of function (21) is attained at points $y_{j i}=$ $y_{j i}^{*}, j=\overline{1, J}, i=\overline{1, I}$. Therefore, constraints (19) have the following form

$$
\sum_{j=1}^{J} c_{0 j}^{T} u_{j}+\gamma+\delta_{r}\left[\sum_{j=1}^{J} u_{j}^{T} z_{j}^{r}+\sum_{j=1}^{J} c_{1 j i_{j}^{*}}^{T} y_{j i_{j}^{*}}^{*}-\gamma\right] \leq \psi, r=\overline{1, R}
$$

since all the other terms in the sum $\sum_{j=1}^{J} c_{1 j}^{T} y_{j}^{*}$ are equal to zero.

Let us introduce vector $\beta \triangleq \operatorname{col}\left(\beta_{1}, \ldots, \beta_{J}\right)$ which contains additional optimization variables such that

$$
\beta_{j} \geq \max \left\{x_{j}^{r}+u_{j} w_{j}^{r}-e_{0}^{T} u_{j}, 0\right\}, j=\overline{1, J} .
$$

Then constraints (19), (20) of problem (18) can be written as

$$
\begin{gathered}
\sum_{j=1}^{J} c_{0 j}^{T} u_{j}+\gamma+\delta_{r}\left[\sum_{j=1}^{J} u_{j}^{T} z_{j}^{r}+\sum_{j=1}^{J} c_{1 j i_{j}^{*}}^{T} \beta_{j}-\gamma\right] \leq \psi, r=\overline{1, R}, \\
x_{j}^{r}+w_{j}^{r T} u_{j}-e_{0}^{T} u_{j} \leq \beta_{j}, \beta_{j} \geq 0, \\
\frac{1}{R} \sum_{r=1}^{R} \delta_{r} \geq \alpha, r=\overline{1, R} .
\end{gathered}
$$

Finally, we obtain a mixed integer linear programming problem whose constraints have linear properties separately for random factors and strategies at the first stage. But the number of constraints is decreased from $2^{J}$ to $J$. Now we have to sort $J$ new variables $\beta_{j}, j=\overline{1, J}$, instead of all vertices of the $J$-dimensional rectangle $V$.

\section{An Example}

Consider the problem of different brands of hairdryers delivery from each supplier to consumers. Assume that the amount $I$ of suppliers is 10 and the amount $J$ of consumers is 10 .

We make a table with the components $c_{0 j i}$ to describe the unit cost of products from each supplier to all consumers in rubles. The components $c_{0 j i}$ determined by analyzed 
information about the cost of different brands of hairdryers from the sites of electrical and household devices distributors. We also use the results of the market analysis of hairdryers and devices for hairstyling in Russia presented in the marketing research by company Discovery Research Group.

Table 1

The cost $c_{0 j i}$ of the suppliers production unit for every consumer, rub.

\begin{tabular}{|l|l|l|l|l|l|l|l|l|l|l|}
\hline$j \backslash i$ & 1 & 2 & 3 & 4 & 5 & 6 & 7 & 8 & 9 & 10 \\
\hline \hline 1 & 3249 & 1039 & 999 & 1599 & 1439 & 1199 & 1789 & 4289 & 1389 & 2789 \\
\hline 2 & 1199 & 2199 & 2400 & 3000 & 2899 & 3199 & 2549 & 4249 & 1879 & 1500 \\
\hline 3 & 2199 & 2499 & 1700 & 1899 & 1449 & 2099 & 2600 & 3800 & 1999 & 1499 \\
\hline 4 & 3149 & 2789 & 1349 & 2999 & 1399 & 1789 & 2099 & 3499 & 1479 & 2349 \\
\hline 5 & 1597 & 1689 & 1465 & 1349 & 1100 & 1265 & 1948 & 2492 & 1498 & 1389 \\
\hline 6 & 3499 & 1999 & 790 & 1789 & 1245 & 2849 & 2199 & 3999 & 1100 & 2499 \\
\hline 7 & 3000 & 1300 & 1390 & 2099 & 2409 & 2415 & 2001 & 3046 & 3904 & 3690 \\
\hline 8 & 3219 & 1879 & 1399 & 2499 & 1789 & 2689 & 2345 & 3450 & 2890 & 3145 \\
\hline 9 & 2790 & 2790 & 1390 & 2490 & 2190 & 1790 & 1690 & 3190 & 2490 & 2590 \\
\hline 10 & 2989 & 2165 & 1289 & 2700 & 1899 & 2900 & 2450 & 3900 & 1845 & 3000 \\
\hline
\end{tabular}

Rows of the table show costs of the production unit for every $j$-th consumer from all suppliers. Note that the costs of the production unit for each supplier are various for different consumers. It is shown in the table's columns. For example, the cost of the third supplier $(i=3)$ production for the sixth consumer $(j=6)$ is 790 rubles, and for the second consumer $(j=2)$ is 2400 rubles. This difference can be explained by the certain factors affecting on the formation of the products cost for a particular consumer. For example, these factors may be a large territorial remoteness of the point of consumption from the supplier, presence or absence of the long-term supply contracts.

Usually the random addition to the cost of the suppliers production slightly changes the original cost. It can be related with discount to increase the consumer demand or with mark-up in the month with holidays. We assume that the random demand doesn't change the initial cost but may deviate for 10 percent both the bigger and the smaller sides. Let the random vector $\bar{Z}_{j}$ have the normal distribution and $3 \sigma=0.1 c_{0 j}$, then $\bar{Z}_{j} \sim \mathcal{N}\left(0 ; 0.001 c_{0 j}^{2}\right)$.

Let the limited purchasing power and the total stock of the products have the following form

$$
\begin{gathered}
d \triangleq \operatorname{col}\left(d_{1}, \ldots, d_{J}\right)=\operatorname{col}(40,40,15,70,150,130,50,230,100,240), \\
h \triangleq \operatorname{col}\left(h_{1}, \ldots, h_{I}\right)=\operatorname{col}(240,340,150,390,300,140,350,230,190,240) .
\end{gathered}
$$

The limited purchasing power depends on the business scale of the consumer, for example, the consumers $1-3$ and $7\left(d_{1}, d_{2}, d_{3}, d_{7}\right)$ likely relate to small companies which are in the process of business formation or markets for which electrical and household devices are not the main kind of goods. At the same time the consumers 8 and $10\left(d_{8}, d_{10}\right)$ are large hypermarkets or hypermarkets specialized in electro-household goods sales.

In case of incorrect delivery planning and unsatisfied demand suppliers has the significant loss including the purchase of an additional products, its urgent delivery to the consumer, and possibly penalties due to the late delivery. Suppose that the value of 
the unsatisfied demand compensation cost is up to the double original cost of goods, i.e., $c_{1 j}=2 c_{0 j}$.

Let a random demand $X_{j}, j=\overline{1,10}$, of the $j$-th consumer for the month have the uniform distribution with parameters $a_{j}$ and $b_{j}$. Let the parameters of the demand distribution for different $j$ consumers, $j=\overline{1,10}$, be equal to

$$
\begin{aligned}
& a \triangleq \operatorname{col}\left(a_{1}, \ldots, a_{J}\right)=\operatorname{col}(25,10,5,50,130,150,35,200,70,230), \\
& b \triangleq \operatorname{col}\left(b_{1}, \ldots, b_{J}\right)=\operatorname{col}(45,35,20,80,160,160,45,250,90,250) ;
\end{aligned}
$$

where the first values of the vectors $a$ and $b$ meets the first consumer's demand parameters, the second values of $a$ and $b$ meets the second consumer's demand parameters, etc. Note that demand characteristics varies near the value of the consumers purchasing power and they must correspond the consumers business scale, which determines the demand for the products of the suppliers.

If there are some damaged products during the delivery or products with hidden defects detected by consumer the supplier have to deliver the missing amount of products to the consumer. The share of possibly damaged hairdryers during delivery is considerably small, also there is a small proportion of hidden defects, so we assume the average percentage $W_{i j}$ of identified defective products is 10 percent for all supplied products, i.e., $\bar{W}_{i j} \sim \mathcal{E}(10)$.

Let $\alpha=0,95$, i.e., we will find the guarantee solution which won't exceed the acceptable level of suppliers loss with the probability 0,95 .

Let us generate 700 points $\bar{x}^{r}, r=\overline{1,700}$, to solve the problem (the technical limitation of the computer on which modelling was carried out don't allow to generate more points).

As a result we obtain the problem solution $u_{j i}, i=\overline{1,10}, j=\overline{1,10}$, which is a preliminary plan of products delivery to customers. This solution characterizes the production amount which every supplier must deliver to his customers such that in case of unsatisfied demand supplier incurs minimal compensation expenses.

The resulting solution is not integer, so it must be rounded to the nearest integer number. The solution of the problem is presented in Table 2. The total amount of the

Table 2

Amount $u_{j i}$ of products delivered in the first stage

\begin{tabular}{|l|l|l|l|l|l|l|l|l|l|l|}
\hline$j \backslash i$ & 1 & 2 & 3 & 4 & 5 & 6 & 7 & 8 & 9 & 10 \\
\hline \hline 1 & 0 & 35 & 0 & 0 & 0 & 0 & 0 & 0 & 0 & 0 \\
\hline 2 & 22 & 0 & 0 & 0 & 0 & 0 & 0 & 0 & 0 & 0 \\
\hline 3 & 0 & 0 & 0 & 0 & 0 & 0 & 0 & 0 & 0 & 14 \\
\hline 4 & 0 & 0 & 0 & 0 & 17 & 0 & 0 & 0 & 49 & 0 \\
\hline 5 & 0 & 0 & 0 & 17 & 74 & 59 & 0 & 0 & 0 & 0 \\
\hline 6 & 0 & 0 & 0 & 0 & 0 & 0 & 0 & 0 & 130 & 0 \\
\hline 7 & 0 & 50 & 0 & 0 & 0 & 0 & 0 & 0 & 0 & 0 \\
\hline 8 & 0 & 109 & 0 & 0 & 121 & 0 & 0 & 0 & 0 & 0 \\
\hline 9 & 0 & 0 & 0 & 0 & 0 & 0 & 100 & 0 & 0 & 0 \\
\hline 10 & 0 & 0 & 150 & 0 & 89 & 0 & 0 & 0 & 2 & 0 \\
\hline
\end{tabular}


hairdryers supplied on the first stage is 1036 pieces that corresponds to the average amount of the 10 stores in Moscow sales for a month (based on the analyses of the marketing research prepared by Discovery Research Group).

Note that the 8-th supplier's production is significantly more expensive for the customers than the production of other suppliers. Therefore the 8-th supplier will necessary compensate the unsatisfied demand and pay a penalty in double cost of goods in the case of defective delivery or hidden defect detection. This is explanation of the absence of any supply from the eighth supplier in Table 2 .

Also Table 2 shows that the majority of consumers prefer to cooperate with the supplier the cost of whom products is cheaper for them than the products cost of other suppliers. Just the small companies $(j=1,2,3,4,7)$ are included in this category. At the same time consumers who are hypermarkets or specialized in electro-household goods sales stores $(j=5,8,10)$ must have several types of products in their collection, so they are guaranteed to purchase products from multiple suppliers.

Note that the production of the 2-nd and the 5-th suppliers have the highest demand. This is explained by the fact that the cost of the production unit is less than the average cost of production of all the suppliers for each individual consumer.

We use optimization software package Opti Toolbox for Matlab to solve problem (18), (24) - (26) based on the data entered before.

It should be noted that in this example an optimization strategy (the amount of hairdryers) is discrete, but because of the high value of production deliveries integer solution can be neglected. Therefore, in order to find a strategy we can use the method developed for the continuous problem.

\section{Conclusion}

In the present paper we suggested a mathematical model of the transport system optimization, describing the interaction of suppliers and consumers, taking into account the random demand. As a model system we chose two-stage stochastic programming problem with quantile criterion and with bilinear loss function (linear separately for random factors and strategies of the first stage). The algorithm for obtaining a guarantee solution for the original stochastic problem is proposed. This solution is based on earlier results of the authors and the one takes into account the peculiarities of the problem. The algorithm is based on a probability measure discretization and the reduction of the original stochastic problem to a mixed integer linear programming problem. An illustrative example is proposed.

Acknowledgements. The work has been supported by Russian Science Foundation (project no. 16-11-00062).

\section{References}

1. Monge G. Mémoire sur la théorie des déblais et de remblais. Histoire de l'Académie Royale des Sciences de Paris, avec les Mémoires de Mathématique et de Physique pour la même année. Paris, 1781.

2. Yudin D.B. Zadachi i metody stokhasticheskogo programmirovaniya. [Problems and Methods of Stochastic Programming]. Moscow, Sovetskoye radio, 1979. (in Russian) 
3. Borodinova I.A., Saraev L.A. [Stochastic Transportation Problem]. Vestnik of Samara State University, 2010, no. 81, p. 16-23. (in Russian)

4. Kibzun A.I., Kan Yu.S. Zadachi stokhasticheskogo programmirovaniya s veroyatnostnymi kriteriyami. [Stochastic Programming Problems with Probabilistic Criteria]. Moscow, FIZMATLIT, 2009. (in Russian)

5. Bogdanov A.B., Naumov A.V. Solution to a Two-Step Logistics Problem in a Quintile Statement. Automation and Remote Control, 2006, vol. 67, issue 12, pp. 1893-1899. DOI: $10.1134 /$ S0005117906120034

6. Kibzun A.I., Khromova O.M. On Reduction of the Multistage Problem of Stochastic Programming with Quantile Criterion to the Problem of Mixed Integer Linear Programming. Automation and Remote Control, 2014, vol. 75, issue 4, pp. 688-699. DOI: 10.1134 /S0005117914040092

7. Kibzun A. Comparison of Two Algorithms for Solving a Two-Stage Bilinear Stochastic Programming Problem with Quantile Criterion. Applied Stochastic Models in Business and Industry, 2015, vol. 31, no. 6, pp. 862-874. DOI: 10.1002/asmb.2115

8. Kibzun A.I., Naumov A.V., Norkin V.I. On Reducing a Quantile Optimization Problem with Discrete Distribution to a Mixed Integer Programming Problem. Automation and Remote Control, 2013, vol. 74, issue 6, pp. 951-967. DOI: 10.1134/S0005117913060064

9. Kibzun A.I., Naumov A.V., Norkin V.I. Reducing Two-Stage Probabilistic Optimization Problems with Discrete Distribution of Random Data to Mixed-Integer Programming Problems. Cybernetics and Systems Analysis, 2014, vol. 50, issue 5, pp. 679-692.

10. Bukan D., Kenigsberg E. Nauchnoye upravleniye zapasami. [Scientific Inventory Management]. Moscow, Nauka, 1967. (in Russian)

11. Brodetskiy G.L. Upravleniye zapasami. [Inventory Management]. Moscow, Eksmo, 2008. (in Russian)

12. Birge J., Louveaux F. Introduction on Stochastic Programming. N.Y., Springer, 1997.

13. Gol'shtein E.G. Teoriya dvoystvennosti $v$ matematicheskom programmirovanii $i$ eyo prilozheniya. [Duality Theory in Mathematical Programming and Its Applications]. Moscow, Nauka, 1971. (in Russian)

Received April 1, 2016

УДК $519.688+519.85+519.852 .33$

DOI: $10.14529 / \mathrm{mmp} 160304$

\title{
МАТЕМАТИЧЕСКОЕ МОДЕЛИРОВАНИЕ ТРАНСПОРТНОЙ СИСТЕМЫ С МИНИМИЗАЦИЕЙ ЗАТРАТ НА ЕЕ ФУНКЦИОНИРОВАНИЕ
}

\section{А.И. Кибзун, О.М. Хромова}

\begin{abstract}
Предлагается оптимизационная математическая модель транспортной системы, в которой осуществляется поставка продукции от нескольких поставщиков в различные пункты потребления с учетом случайного спроса. Модель системы представляет собой двухэтапную задачу стохастического программирования, на первом этапе которой происходит формирование первичного плана поставщиков. На втором этапе производится распределение товаров между пунктами потребления при минимизации расходов по компенсации недостатка товара, возникающего за счет случайного спроса. В модели учитываются случайные потери, возникающие при перевозке продукции и выявлении дефекта продукции. Суммарные затраты на функционирование рассматриваемой транспортной системы минимизируются. В статье предложен алгоритм решения
\end{abstract}


задачи, основанный на сведении сформулированной задачи после дискретизации к эквивалентной задаче смешанного целочисленного программирования. Рассматривается пример.

Ключевые слова: математическое программирование; стохастическое программирование; функиия квантили; двухэтапная задача; транспортная задача.

\section{Литература}

1. Monge, G. Mémoire sur la théorie des déblais et de remblais. Histoire de l'Académie Royale des Sciences de Paris, avec les Mémoires de Mathématique et de Physique pour la même année / G. Monge. - Paris, 1781.

2. Юдин, Д.Б. Задачи и методы стохастического программирования / Д.Б. Юдин. - М.: Советское радио, 1979.

3. Бородинова, И.А. Стохастическая транспортная задача / И.А. Бородинова, Л.А. Сараев // Вестник СамГУ. - 2010. - № 81. - С. 16-23.

4. Кибзун, А.И. Задачи стохастического программирования с вероятностными критериями / А.И. Кибзун, Ю.С. Кан. - М.: Физматлит, 2009.

5. Наумов, А.В. Решение двухэтапной задачи логистики в квантильной постановке / А.В. Наумов, А.Б. Богданов // Автоматика и телемеханика. - 2006. - № 12. - С. 36-42.

6. Кибзун, А.И. О сведении многоэтапной задачи стохастического программирования с квантильным критерием к задаче смешанного целочисленного линейного программирования / А.И. Кибзун, О.М. Хромова // Автоматика и телемеханика. - 2014. - № 4. C. $120-133$.

7. Kibzun, A. Comparison of Two Algorithms for Solving a Two-stage Bilinear Stochastic Programming Problem with Quantile Criterion / A. Kibzun // Applied Stochastic Models in Business and Industry. - 2015. - V. 31, № 6. - P. 862-874.

8. Кибзун, А.И. О сведении задачи квантильной оптимизации с дискретным распределением к задаче смешанного целочисленного программирования / А.И. Кибзун, А.В. Наумов, В.И. Норкин // Автоматика и телемеханика. - 2013. - № 6. - С. 66-86.

9. Кибзун, А.И. Сведение задач двухэтапной вероятностной оптимизации с дискретным распределением случайных данных к задачам частично целочисленного программирования / А.И. Кибзун, А.В. Наумов, В.И. Норкин // Кибернетика и системный анализ. - 2014. - Т. 50, № 5. - С. 34-48.

10. Букан, Дж. Научное управление запасами / Дж. Букан, Э. Кенигсберг. - М.: Наука, 1967.

11. Бродецкий, Г.Л. Управление запасами / Г.Л. Бродецкий. - М.: Эксмо, 2008.

12. Birge, J. Introduction on Stochastic Programming / J. Birge, F. Louveaux. - N.-Y.: Springer, 1997.

13. Гольштейн, Е.Г. Теория двойственности в математическом программировании и ее приложения / Е.Г. Гольштейн. - М.: Наука, 1971.

Андрей Иванович Кибзун, доктор физико-математических наук, профессор, кафедра «Теория вероятностей», Московский авиационный институт (г. Москва, Российская Федерация), kibzun@mail.ru.

Ольга Михайловна Хромова, кандидат физико-математических наук, кафедра «Теория вероятностей», Московский авиационный институт (г. Москва, Российская Федерация), khromova-om@mail.ru.

Поступила в редакиию 1 апреля 2016 г. 